\title{
Effect of Non-Polar Bioactive Molecules of Tagetus on Second Stage Larvae of Meloidogyne javanica in Lab Conditions
}

\author{
Abhilasha Srivastava* \\ Department of Science and Technology, New Delhi, India \\ *Corresponding author
}

\begin{tabular}{|l|}
\hline K e y w o r d s \\
Allelochemicals, \\
Allelopathy, Tagetus, \\
$\begin{array}{l}\text { Meloidogyne javanica, } \\
\text { Solvents, } \\
\text { Biopesticides }\end{array}$ \\
\hline Article Info \\
\hline $\begin{array}{l}\text { Accepted: } \\
\text { 26 September } 2017 \\
\text { Available Online: } \\
\text { 10 November } 2017\end{array}$ \\
\hline
\end{tabular}

\section{Introduction}

Chemical control of plant-parasitic nematode, essentially, involves the use of synthetic nematicides. As we know that nematodes are microscopic pathogens and create heavy loss in crop yield. Root-knot nematodes are sedentary endoparasites and most damaging agricultural pests, attacking a wide range of crops. The infection starts with root penetration of second stage juveniles $\left(\mathrm{J}_{2}\right)$ hatched in soil from egg encapsulated in egg masses laid by females on the infected roots.
Nematode infestation is considered as a prime constraints in realizing optimum yield potential of cultivated crops causing approximately $15-20 \%$ yield losses.

India produced 78.2 million tonnes of vegetables from 5.73 million hectare of land. Tomato is one of the important and popular vegetables grown in India and other parts of the world. It is a rich source of soluble sugars, several organic acids (Citric and Malic acids), 
Mineral salts and large quantities of Vitamins $\mathrm{A}, \mathrm{B}_{2}$ and $\mathrm{C}$. The vegetable is attacked by root-knot nematode. In India, reduction in the yield of tomatoes due to root-knot nematode has been reported 26.5 to $73.3 \%$. The management of this nematode has been carried out by several workers (Akhtar and Mahmood, 1993; Das and Mishra, 2003; Dwivedi et al., 2004; Gaur and Prasad, 1990).

So, it is the necessary to control these tiny, harmful worms in field conditions. However, apart from very high cost of chemical pesticides, increased concern for the environment has necessitated a reduction in amount of nematicide used for nematode control. Additionally, there has been an increase in the intensity of search for other efficient, ecologically sound and safe control methods.

Tagetus is an ornamental plant. It has several pesticidal properties in which nematicidal activity is well known in field conditions. We are using this plant as green technology which is safe for environment and easily available in our country. Total work is in the direction to extract particular potential molecules from plant which will be the pin-point for the mortality rate of second stage larvae of Meloidogyne javanica in field conditions. Allelochemicals refer mostly to the secondary metabolites released by intact live plant into their surrounding and are by product of primary metabolic process. Different classes of allelochemicals e.g. phenolic acids, caumarins, flavonoids, terpenoids, alkaloids and sulphides etc. have been identified. Allelopathy has direct (toxicity) or indirect (i.e. by supporting growth of biocarbon agents) effect on pests.

\section{Materials and Methods}

Plant of Tagetus has been grown in a trapping system, which was developed with the help of
Butchner funnel of $110 \mathrm{~cm}$ diameter and conical flask of $500 \mathrm{ml}$. capacity. The sieve plate of buchner funnel has been cut and firstly muslin cloth was placed in it, then funnel was filled with the soil (loamy soil) of field capacity. The 2-3 seeds of Tagetus were grown in every trapping system. After the seedling growth when plants attained some height one plant was allowed to grow and other was thinned. After attaining the maturity (at the time of flowering) plant was taken out from the system and shade dried. After that the roots were cut into small pieces and powdered. Then it was processed for the recovery of biocidal compounds.

Firstly, known quantity of the material was mechanically stirred in required solvent system for 2-3 hours at room temperature and then filtered. Filtrate was evaporated to minimum amount under vacuum at $50^{\circ} \mathrm{C} \pm$ $1^{\mathrm{O}} \mathrm{C}$. The concentrated solution was transferred to a separating funnel and partitioned with some amount of ethyl acetate and hexane. The mixture was vigorously shaken for two hours and kept overnight to settle the different layers. By this allelocompounds got fractionated into two major groups (a) Polar (Which remained with $\mathrm{H}_{2} \mathrm{O}$ layer) (b) Non-polar (Settle down with ethyl acetate layer).

Both were removed carefully and kept separately. Finally the ethylacetate layer was evaporated to dryness under vacuum at $50 \pm$ $10^{\circ} \mathrm{C}$. After that allelocompounds were recovered by using fractional crystallization technique. For the recovery of compounds, different solvents of different polarity were used. Before crystallization a number of information like numbers of compounds present in each fraction and their polarity etc. were being generated with the help of thin layer chromatography and then compounds were fractionally crystallized by selecting the suitable polarity of solvents. 


\section{Analysis of compounds}

\section{Thin layer chromatoraphy method}

TLC methods were developed to analyze and checking the purity of the isolated compounds of Tagetus root exudates present in each fraction.

After that bioefficacy of extracted compounds were evaluated against second stage of juveniles of Meloidogyne javanica in the laboratory and in pots on Tomato plants.

For bioefficacy evaluation initially the emulsified concentrations of the extracted fractions were converted into suitable concentrations.

EC formulations of different concentrations were tested against the second stage juveniles for which cultures were maintained in the laboratory of the Department of Botany, P.P.N. College, Kanpur on Chickpea and Sisbanea spp.

\section{Preparation of EC Formulation}

For bioassay study initially the isolated compounds were converted into suitable EC and EW formulations. Non-polar i.e. hexane, ethyl acetate and acetone soluble fractions were emulsified separately at $10 \%$ emulsifiable concentrate (EC) by taking the required quantity of products and adding them (10\%) tween 80 as emulsifier and $80 \%$ xylene. ECs were obtained by constantly high speed agitating the mixture for two-three hours.

\section{Preparation of Test Solution}

Test solutions of different concentrations were prepared by taking the appropriate amount of EC diluting it in a definite volume of water.

\section{Formula used for preparation of concentration}

The amount for each experiment was decided on the basis of following formula:

ai required in Test solution $\mathrm{x}$ Volume of solution

Amount of EC $=$

$\%$ ai in formulation

\section{Bioassay Test}

Second stage juveniles $\left(\mathrm{J}_{2}\right)$ of root-knot nematode were allowed to hatch from egg masses obtained from culture maintained on Chick pea in Dept. of Botany, P.P.N. College, Kanpur in earthen pot.

Experiments for bioefficacy evaluation of extracted compounds were conducted on freshly hatched second stage juveniles in petriplates of $12 \mathrm{ml}$.

Capacity, $9 \mathrm{ml}$. distilled water was poured in each petriplate and with the help of micropippette desired quantity of formulations were added and mixed well.

One $\mathrm{ml}$. of suspension of freshly hatched larvae were added to each petriplate and that make the total volume of water of $10 \mathrm{ml}$. and plates were loosely caped by another petriplates and were kept for 24,48 and 72 hours at room temperature $\left(30^{\circ}+1^{\circ} \mathrm{C}\right)$.

All treatments were replicated thrice. A set of control was also placed containing only xylene and tween-80.

After specific time gap, the treated suspension was stirred and one $\mathrm{ml}$. of suspension was taken out and transfer to another petri-plate containing water to reduce chemical toxicity much more below than its toxic level and to observe the revival of larvae if there was any. 


\section{Results and Discussion}

\section{Recovery and Purity of biocidal compounds}

Approximately $2 \mathrm{~kg}$ of Tagetus roots were processed for the recovery of biocidal compounds of different category viz. polar and non-polar category. A total of six different fractions named as A, B, C, D, E and $\mathrm{F}$ as per their clear-cut solubility in different polarity of solvents viz. hexane, dichloromethane, ethylacetate, acetone, methanol and water were recorded. TLC methods were developed to analyze the extracted fractions for their exact purity and total number of compounds present in each fraction. Silica gel of TLC grade was observed to be the appropriate coating materials for non-polar compounds. Highly non-polar compound hexane soluble compound resolved best in $\mathrm{n}$-hexane while ethyl-acetate compounds resolved in 60: $40 \mathrm{n}$ hexane and ethyl-acetate mixture. All fractions were found more than $90 \%$ pure as a single compound as per TLC analysis.

\section{Effect on juveniles}

The activity of EC formulations developed separately by isolated fractions like A, B and $\mathrm{C}$ of Tagetus root exudate biocidal compounds varied according to compound doses and the time of exposures obtained observations are revealed in table 1-3. A great difference, in all respect, in the toxicity of all the developed formulations was observed. Results clearly indicated that formulations developed from non-polar fractions exhibit severe impact on the mortality rate and paralysis of second stage juveniles of Meloidogyne javanica. But in between three of non-polar compounds maximum juveniles mortality rate at different exposure times was achieved by the formulations developed from highly non-polar fraction i.e. hexane (A, Table 1) followed by ethylacetate and acetone (B, C Table 2 and 3). Emulsion concentrate formulation developed from less non-polar fraction was found practically least effective at the same concentration and at maximum time of exposure $(72 \mathrm{~h})$.

Results indicate that the polarity of the extracted compounds of Tagetus root exudate remained as the key factor in imparting the toxicity against second stage juveniles of Meloidogyne javanica.

Results also indicate that as the polarity of solvent changes from non-polar to polar even every high concentration is not much effective in comparison of non-polar compounds.

Table.1 Effect of hexane soluble compounds

\begin{tabular}{|l|c|c|c|c|c|c|c|c|c|c|c|c|}
\hline $\begin{array}{c}\text { Conc. } \\
\mu \mathrm{g} \mathrm{ml}^{-1}\end{array}$ & \multicolumn{3}{|c|}{$\begin{array}{c}\text { Percentage mortality } \\
\text { after } 24 \text { hours. }\end{array}$} & \multicolumn{4}{c|}{$\begin{array}{c}\text { Percentage mortality } \\
\text { after 48 hours. }\end{array}$} & \multicolumn{5}{c|}{ After 72 hours. } \\
\hline & $\mathrm{A}_{1}$ & $\mathrm{~A}_{2}$ & $\mathrm{~A}_{3}$ & Aver & $\mathrm{A}_{1}$ & $\mathrm{~A}_{2}$ & $\mathrm{~A}_{3}$ & Aver & $\mathrm{A}_{1}$ & $\mathrm{~A}_{2}$ & $\mathrm{~A}_{3}$ & Aver \\
\hline 25 & 3 & 3 & 4 & 3.3 & 8 & 10 & 8 & 8.7 & 15 & 18 & 20 & 17.6 \\
\hline 50 & 7 & 8 & 7 & 7.3 & 14 & 15 & 18 & 15.7 & 35 & 38 & 42 & 38.3 \\
\hline 100 & 26 & 28 & 25 & 26.3 & 30 & 35 & 38 & 34.3 & 50 & 55 & 56 & 53.6 \\
\hline 150 & 40 & 42 & 51 & 44.3 & 55 & 60 & 62 & 59.0 & 89 & 94 & 91 & 91.3 \\
\hline 200 & 98 & 98 & 100 & 98.7 & 100 & 100 & 100 & 100.0 & 100 & 100 & 100 & 100.0 \\
\hline
\end{tabular}


Table.2 Effect of ethyl acetate soluble compounds

\begin{tabular}{|l|c|c|c|c|c|c|c|c|c|c|c|c|}
\hline $\begin{array}{c}\text { Conc. } \\
\mu \mathrm{g} \mathrm{ml} \mathrm{ml}^{-1}\end{array}$ & \multicolumn{3}{|c|}{ Percentage mortality after } & \multicolumn{3}{c|}{ Percentage mortality after } & \multicolumn{5}{c|}{ After 72 hours. } \\
\hline & $\mathrm{A}_{1}$ & $\mathrm{~A}_{2}$ & $\mathrm{~A}_{3}$ & Aver & $\mathrm{A}_{1}$ & $\mathrm{~A}_{2}$ & $\mathrm{~A}_{3}$ & Aver & $\mathrm{A}_{1}$ & $\mathrm{~A}_{2}$ & $\mathrm{~A}_{3}$ & Aver \\
\hline 25 & 3.0 & 4.2 & 4.0 & 3.7 & 7.5 & 8.2 & 7.1 & 7.6 & 9.0 & 10.4 & 8.8 & 9.4 \\
\hline 50 & 6.0 & 7.2 & 6.0 & 6.4 & 11.0 & 14.8 & 12.4 & 12.7 & 15.0 & 18.2 & 16.0 & 16.4 \\
\hline 100 & 27.2 & 32.0 & 28.0 & 29.6 & 48.0 & 52.4 & 46.3 & 48.9 & 50.2 & 63.0 & 64.0 & 59.6 \\
\hline 150 & 50.0 & 52.5 & 53.5 & 52.0 & 73.0 & 78.2 & 72.0 & 74.4 & 84.3 & 82.3 & 80.2 & 82.3 \\
\hline 200 & 98 & 100 & 100 & 98.7 & 100 & 100 & 100 & 100.0 & 100 & 100 & 100 & 100.0 \\
\hline
\end{tabular}

Table.3 Effect of acetone soluble compounds

\begin{tabular}{|c|c|c|c|c|c|c|c|c|c|c|c|c|}
\hline $\begin{array}{c}\text { Conc. } \\
\mu \mathrm{g} \mathrm{ml}\end{array}$ & \multicolumn{3}{|c|}{$\begin{array}{c}\text { Percentage mortality } \\
\text { after } 24 \text { hours. }\end{array}$} & \multicolumn{3}{c|}{$\begin{array}{c}\text { Percentage mortality } \\
\text { after 48 hours. }\end{array}$} & \multicolumn{5}{c|}{ After 72 hours. } \\
\hline & $\mathrm{A}_{1}$ & $\mathrm{~A}_{2}$ & $\mathrm{~A}_{3}$ & Aver & $\mathrm{A}_{1}$ & $\mathrm{~A}_{2}$ & $\mathrm{~A}_{3}$ & Aver & $\mathrm{A}_{1}$ & $\mathrm{~A}_{2}$ & $\mathrm{~A}_{3}$ & Aver \\
\hline 100 & 7 & 10 & 7 & 8.0 & 9 & 11 & 8 & 9.3 & 15 & 18 & 20 & 17.7 \\
\hline 200 & 12 & 12 & 15 & 13.0 & 14 & 15 & 15 & 14.7 & 27 & 29 & 24 & 26.7 \\
\hline 300 & 28 & 45 & 42 & 38.3 & 32 & 45 & 42 & 39.6 & 35 & 48 & 45 & 42.7 \\
\hline 400 & 39.0 & 38 & 32.2 & 36.4 & 44 & 48 & 40 & 44 & 50 & 51 & 44 & 48.3 \\
\hline 500 & 36.2 & 49 & 34.8 & 40.0 & 42 & 56 & 46 & 48.0 & 48 & 58 & 50 & 52.0 \\
\hline 600 & 42.0 & 45 & 50 & 45.6 & 53 & 55 & 60 & 56 & 60 & 60 & 62 & 60.6 \\
\hline 700 & 59 & 55 & 52 & 55.3 & 70 & 76 & 76 & 74 & 73 & 78 & 76 & 75.7 \\
\hline
\end{tabular}

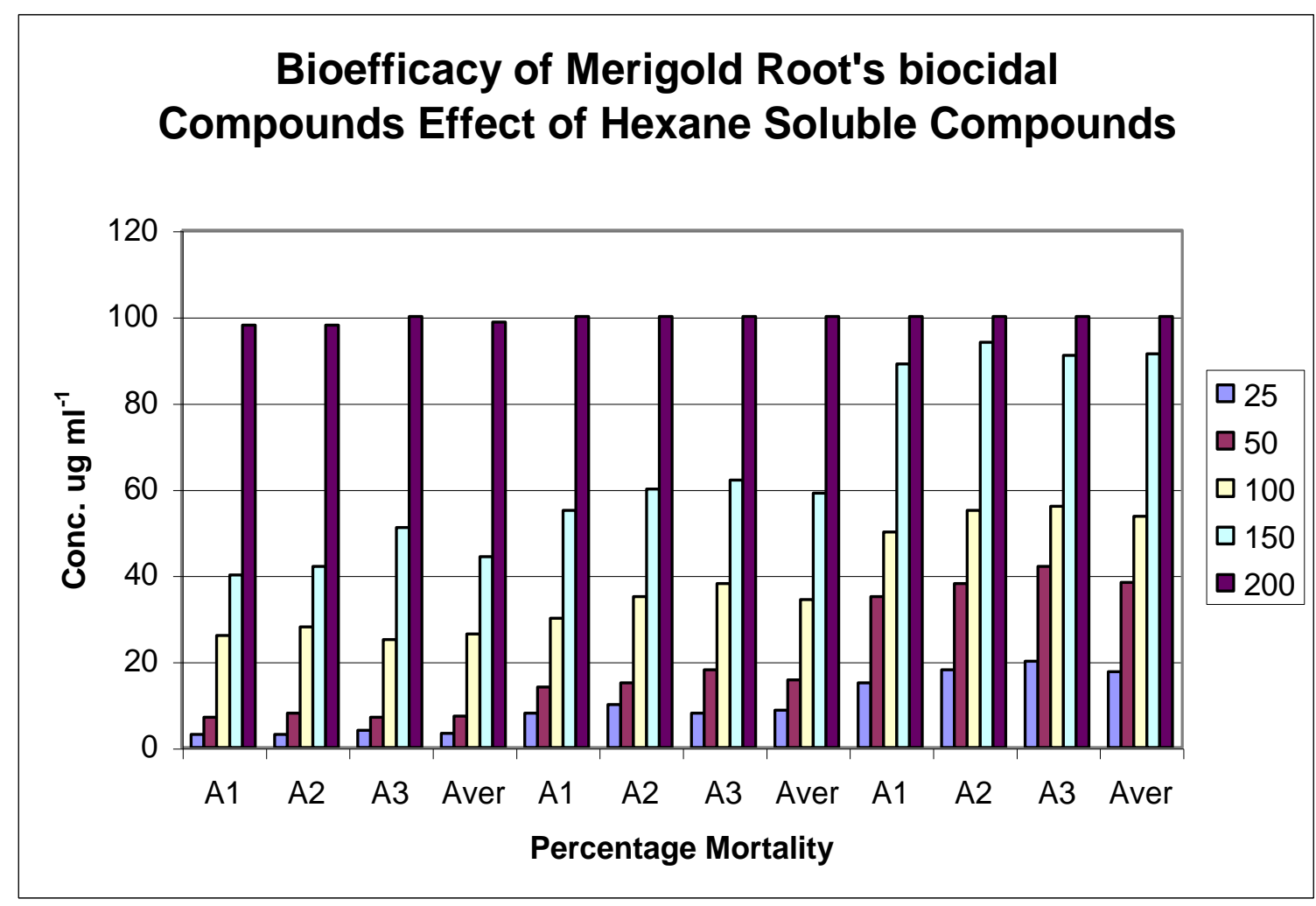




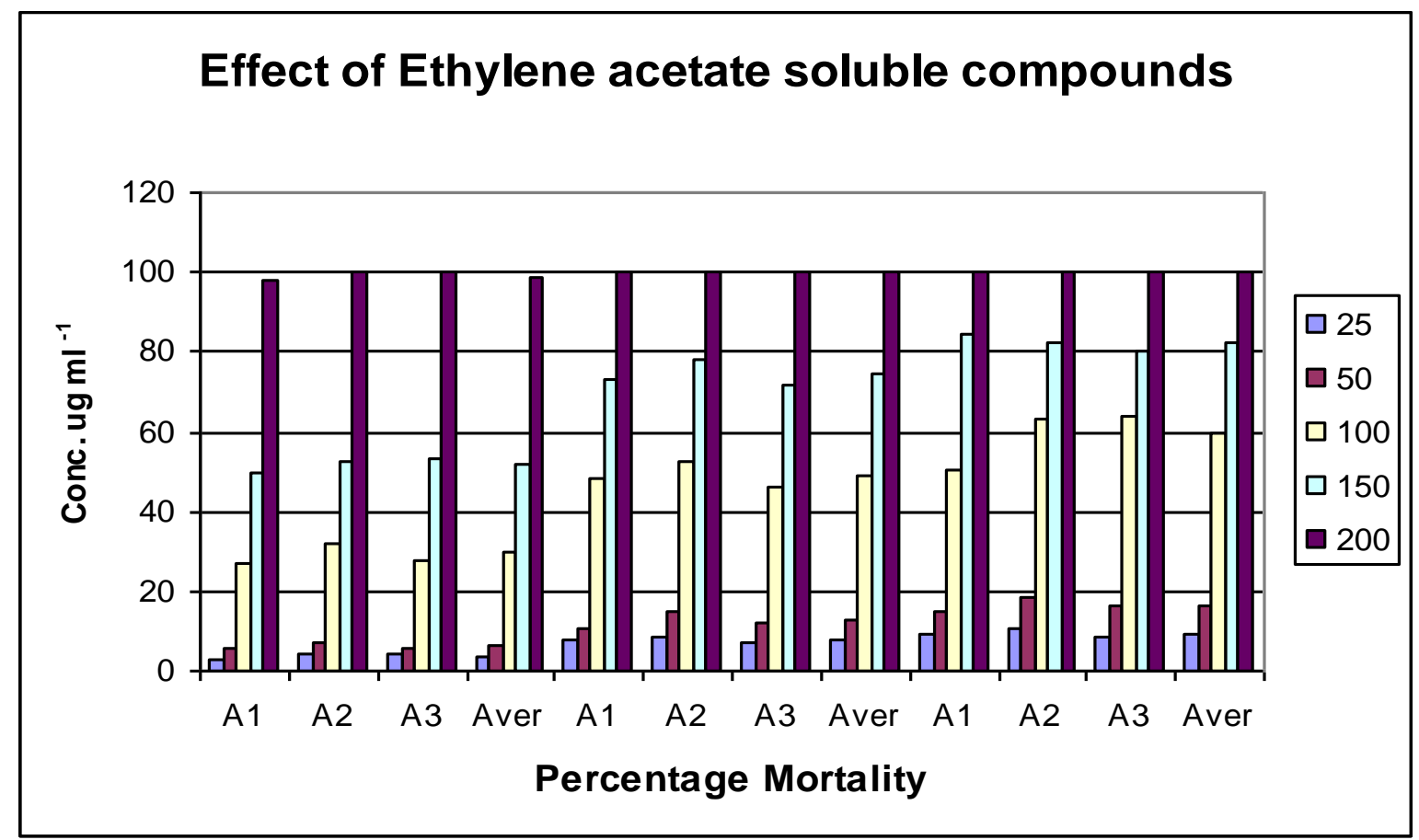

\section{Effect of Acetone Soluble Compounds}
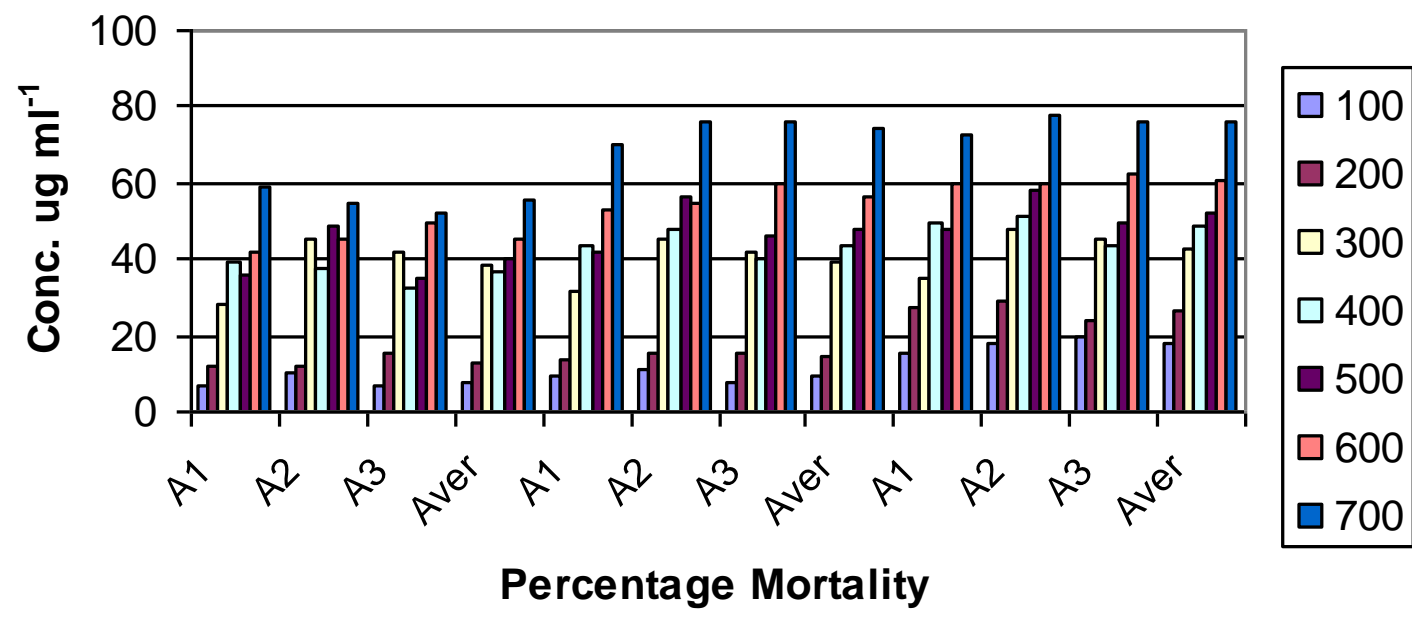

Percentage Mortality

The results suggest that the biocidal compounds extracted from the Tagetus root especially the non-polar group of compounds possess molecules with tremendous nematicidal activity, which can be utilized effectively as a new control strategy with minimal or nil environmental impact for effective control and management of Meloidogyne spp. and possibly other nematodes in agricultural and other important commercial crops. In all directions emulsion concentrate formulation developed from 
highest non-polar compounds was found most effective at the same concentrations in field conditions.

After lab experiments, all the results indicate that the polarity of extracted compounds of Tagetus root exudates remained as the key factor in imparting the toxicity against second stage of juveniles of Meloidogyne javanica in lab conditions Therefore, the formulations developed especially from non-polar fraction hexane was found detrimental to the juveniles and Root Galls.

The results suggested that the biocidal compounds extracted from the Tagetus root, especially, the non-polar group of compounds posses molecules with tremendous nematicidal activity, which can be utilized effectively as a new control strategy with minimal or nil environmental impact for effective control and management of Meloidogyne spp. and possibly other nematodes in agricultural and other important commercial crops. It will also curtial the budget of chemical pesticides.

\section{Acknowledgement}

I am thankful to department of Science and Technology for their financial assistance and the Principal and Head of the Department of
Botany, P.P.N. College, Kanpur for providing the infrastructural and reprographic facilities during the course of this study.

\section{References}

Akhtar, M. and Mahmood 1, 1993. Control of plant parasitic nematode with Nimin and some plant oil by bare root dip treatment. Namat Medit., 21: 89-92.

Das, Dibakar and Mishra, S.D., 2003. Effect of neem seed powder and neem based formulations for the management of $M$. incognita, Heterodera Cajani and Rotylenchus reinformis infesting pigeon pea. Ann. Pl. Prot. Sci. 11 (1): 110-115.

Dwivedi, B.K., Singh, S.P.; Logani, R.; Tiwari, S.S.; Sant, A.K. and Yadav, S.; 2004. Comparative efficacy of Neem based pesticides and the chemicals for the management of $M$. incognita in Abelmaschus esculentus L., National Symposium on Pesticides; Myths. Realities. Remedies and Pesticides Expo. 2004. Organised by Society of pesticides Science India, Abstract: 85.

Gaur, H.S. and Prasad, S.K. 1990. Population studies on Meloidogyne incognita on eggplant, Solanum melongena and its effect on the host. Ind. J. of Nematol. 10: 40-52.

\section{How to cite this article:}

Abhilasha Srivastava. 2017. Effect of Non-Polar Bioactive Molecules of Tagetus on Second Stage Larvae of Meloidogyne javanica in Lab Conditions. Int.J.Curr.Microbiol.App.Sci. 6(11): 3484-3490. doi: https://doi.org/10.20546/ijcmas.2017.611.410 